\title{
Receptor Tyrosine Kinase Inhibition
}

National Cancer Institute

\section{Source}

National Cancer Institute. Receptor Tyrosine Kinase Inhibition. NCI Thesaurus. Code C40704.

A process that negatively regulates the intracellular catalytic activities that originate with the binding of a tyrosine kinase-associated transmembrane receptor with its cognate ligand. This process is involved in regulation of signaling related to cellular division, cellular differentiation and morphogenesis. 